\title{
Sensitivity of lipids and their isotopic composition to shifting carbon cycle dynamics along a coastal marine- freshwater wetland gradient
}

\author{
JEROME BLEWETT, RICHARD D. PANCOST AND \\ DAVID NAAFS
}

University of Bristol

Presenting Author: jerome.blewett@bristol.ac.uk

Tropical wetlands are the largest natural emitters of methane to the atmosphere. However, the operation of both the modernday and past wetland methane cycle, particularly in the tropics, is poorly constrained. Because of their inherently high organic matter preservation and diverse lipid assemblages, biomarkers and their $\delta 13 \mathrm{C}$ values offer a promising avenue for fingerprinting methane-cycling processes in these environments [1], [2]. However, these techniques are currently limited by an incomplete picture of the microbial communities in modern tropical wetland environments and, by extension, the sources and biogeochemical significance of the lipids they produce.

In order to address these challenges, we integrated the analysis of a wide range of archaeal and bacterial lipids in tropical wetlands and their $\delta 13 \mathrm{C}$ values with the high-resolution analysis of microbial community composition via $16 \mathrm{~S}$ sequencing. We focused on cores collected along a nutrient, $\mathrm{pH}$ and vegetation transect in Panama, encompassing marine-influenced wetland sediments through to rainwater-fed acidic peats. As well as providing some of the first constraints on the microbial ecology of these settings, we used this dataset to i) explore the influence of methanogenic community structure and pathways on the carbon isotopic composition of GDGT derivatives; ii) assess whether the relative abundance of specific lipid classes (e.g., BDGTs and archaeol) have potential as chemotaxonomic markers for specific microbial groups in these settings, and iii) explore the influence of methanotroph community structure on the carbon isotopic composition of hopanoids. Moreover, by harnessing our global dataset of microbial lipids in wetlands [3], we were able to expand some of these methane-cycle insights to a global-scale.

Collectively, this sets a baseline for a more nuanced analysis of the methane cycle in tropical wetlands as well as other environments, and provides a robust, modern framework for the application of biomarker proxies to reconstruct tropical wetland carbon cycle-climate dynamics in the past.

[1] Blewett, Naafs, Gallego-Sala \& Pancost (2020), Organic Geochemistry 148, 104080.

[2] Inglis, Naafs, Zheng, Schellekens \& Pancost (2019), Geochimica Cosmochimica Acta 260, 244-256.

[3] Naafs et al (2017), Geochimica Cosmochimica Acta 208, 285-301. 